\title{
Granulocyte Macrophage Colony-stimulating Factor Is Overproduced by Keratinocytes in Atopic Dermatitis Implications for Sustained Dendritic Cell Activation in the Skin
}

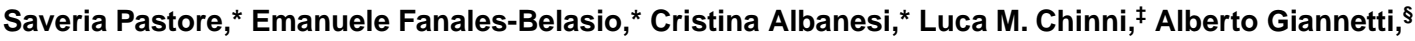 \\ and Giampiero Girolomoni* \\ * Laboratory of Immunology, and ${ }^{\ddagger}$ VIII Division of Dermatology, Istituto Dermopatico dell'Immacolata, IRCCS, 00167 Rome; and \\ ${ }^{\S}$ Department of Dermatology, University of Modena, 41100 Modena, Italy
}

\begin{abstract}
Lesional skin of atopic dermatitis (AD) harbors high numbers of dendritic cells with enhanced stimulatory capacity for $\mathrm{T}$ lymphocytes. In this study, lesional AD skin was shown to stain heavily in both epidermal and dermal compartments for GM-CSF, a cytokine crucial to dendritic cell functions. Keratinocyte cultures established from uninvolved skin of $A D$ patients exhibited markedly increased spontaneous and PMA-stimulated release of GM-CSF compared with keratinocytes from nonatopic controls. Correspondingly, keratinocytes from AD patients showed higher constitutive as well as PMA-induced GM-CSF gene expression. Larger amounts of GM-CSF were produced by AD keratinocytes, also in response to IL-1 $\alpha$, but not after stimulation with LPS, lipoteichoic acid, or staphylococcal enterotoxin B. Hydrocortisone reduced GM-CSF gene expression and protein release in both atopic and control keratinocytes. Supernatants from atopic keratinocytes were able to strongly stimulate PBMC proliferation in a GM-CSF-dependent manner. Moreover, conditioned medium from PMA-treated AD keratinocytes, together with exogenous IL-4, could support phenotypical and functional maturation of peripheral blood precursors into dendritic cells. Enhanced production of GM-CSF by keratinocytes may contribute relevantly to the establishment and chronicity of AD lesions, in particular to the increased number, sustained activation, and enhanced antigen-presenting functions of dendritic cells. (J. Clin. Invest. 1997. 99:3009-3017.) Key words: inflammation • atopic dermatitis $\bullet$ antigen-presenting cells $\bullet$ cytokines $\bullet$ epithelium
\end{abstract}

\section{Introduction}

Atopic dermatitis $(\mathrm{AD})^{1}$ is a chronic and relapsing inflammatory skin disease, characterized by typically distributed eczem-

Address correspondence to Saveria Pastore, Laboratory of Immunology, Istituto Dermopatico dell'Immacolata, IRCCS, Via dei Monti di Creta, 104, 00167 Rome, Italy. Phone: 39-6-6646-4718; FAX: 39-66646-4705; E-mail: pastore@idi.it

Received for publication 6 November 1996 and accepted in revised form 27 March 1997.

1. Abbreviations used in this paper: $\mathrm{AD}$, atopic dermatitis; $\mathrm{DC}$, dendritic cells; LC, Langerhans cell; RT, reverse transcription.

J. Clin. Invest.

(c) The American Society for Clinical Investigation, Inc.

0021-9738/97/06/3009/09 \$2.00

Volume 99, Number 12, June 1997, 3009-3017 atous skin lesions. In many cases, it is associated with elevated serum IgE levels, peripheral blood eosinophilia, as well as rhinoconjunctivitis and/or bronchial asthma. Genetic susceptibility, abnormal lipid synthesis with epidermal barrier dysfunction, and altered inflammatory and immune responses to irritants and allergens are supposed to contribute to AD pathogenesis (1). Acute and chronic skin lesions in AD are characterized by the infiltration of activated T cells, predominately $\mathrm{CD}^{+}$, and monocyte macrophages. Although eosinophils are not prevalent by routine histology, chronic AD is associated with extensive dermal deposition of eosinophilderived proteins (1). Furthermore, lesional skin of AD patients exhibits an increased number of cells belonging to the dendritic cell (DC) lineage, including epidermal Langerhans cells (LC), dermal DC, and a distinct population of epidermal CD1a ${ }^{+}$DC expressing CD1b and/or CD36 (2-4). An additional characteristic of DC in AD is the markedly upregulated expression of the high affinity receptor for $\operatorname{IgE}(\mathrm{Fc} \in \mathrm{RI})$, especially in this last DC population (5).

DCs represent the most potent antigen-presenting cells for the activation of $\mathrm{T}$ lymphocytes and they are well represented in tissues forming an interface with the environment such as the skin and respiratory mucosae (6). Interestingly, epidermal and dermal DC present in AD lesions express activation markers such as B7-1 and B7-2 (7). In addition, epidermal LC isolated from $\mathrm{AD}$ lesions display enhanced stimulatory capacity towards autologous peripheral blood $\mathrm{T}$ cells in the absence of exogenously added antigen (4), thus providing a fundamental mechanism for the perpetuation of immune inflammation in the skin. In this context, expression of the FceRI by DC may be pivotal for more efficient presentation of allergens that penetrate the skin to T lymphocytes $(8,9)$. In an analogous disease (i.e., atopic asthma), the number of DC populating the bronchial mucosa is also significantly higher than in healthy control subjects, and an important involvement of DC in the asthmatic inflammation has been suggested $(10,11)$.

The pattern of cytokines expressed locally is critical in modulating the nature, extent, and persistence of inflammation in AD (12). Keratinocytes, the major epidermal cell population, are known to be activated by a variety of stimuli, and to synthesize and release several cytokines with a modulatory activity on skin immune responses. In particular, keratinocytes can produce GM-CSF, a cytokine essential for DC development and deeply involved in the regulation of DC functions (13). In this study, lesional skin of AD patients was shown to stain heavily for GM-CSF in both epidermal and dermal compartments as compared with nonlesional skin. In addition, keratinocytes cultured from AD patients produced, spontaneously or after stimulation, high amounts of GM-CSF as compared with keratinocytes from nonatopic controls. Finally, conditioned medium from stimulated AD keratinocyte cul- 
tures could support the differentiation of $\mathrm{CD} 1 \mathrm{a}^{+} \mathrm{DC}$ from peripheral blood precursors.

\section{Methods}

Subjects. Eight patients with moderate to severe chronic AD were included in the study. Patients had definite AD diagnosed according to standard criteria (14). They were not receiving any systemic therapy for at least $2 \mathrm{wk}$ before testing, and the only medications allowed were limited amounts of topical corticosteroids. Clinical details are shown in Table I. Punch biopsies were taken from nonmedicated lesional skin of three AD patients (No. 1, 2, and 4), from uninvolved skin of two patients (No. 2 and 4), and from three nonatopic controls (No. 1, 3, and 6). Epidermal sheets for keratinocyte cultures were obtained from the roof of suction blisters raised on normal-looking skin of the forearms of all eight AD patients included in the study. Control skin was obtained from four healthy, nonatopic individuals (four females, 20 to $40 \mathrm{yr}$; mean age $28 \mathrm{yr}$ ) undergoing plastic surgery (mammoplasty or abdominoplasty) (No. 1-4). In two additional subjects (males, 36 and $50 \mathrm{yr}$ ), epidermis was obtained from suction blisters produced on normal skin of the forearms (No. 5 and 6). Control subjects had no personal or family history of $\mathrm{AD}$, asthma, or hay fever, and serum IgE levels were within normal limits. Informed consent was obtained from all subjects, and the study was approved by the Istituto Dermopatico dell'Immacolata Ethical Committee.

Reagents and antibodies. PMA, LPS (055:B5 from Escherichia coli), and lipoteichoic acid (from Staphylococcus aureus) were purchased from Sigma Chemical Co. (St. Louis, MO). Staphylococcal enterotoxin B was purchased from Toxin Technology, Inc. (Sarasota, FL). Recombinant human IL-1 $\alpha$ and IL-4 were obtained from Genzyme, Corp. (Cambridge, MA). Recombinant human GM-CSF was a generous gift from Dr. G. Fincato (Novartis, Origgio, Italy).

Mouse anti-human GM-CSF ( $\operatorname{IgG} 1) \mathrm{mAb}$ was from Genzyme, Corp.; anti-CD1a (BB5, IgG1) and FITC-conjugated anti-CD1a were from Serotec Ltd. (Kidlington, Oxford, UK); mAbs anti-HLADR (L243, IgG2a), FITC-conjugated anti-HLA-DR, anti-CD16 (GO22, IgG1), anti-CD19 (4G7, IgG1), and anti-CD14 (MФP9, $\mathrm{IgG2b}$ ) were obtained from Becton Dickinson \& Co. (San Jose, CA); anti-CD23 (Tu-1, IgG3), anti-CD80 (BB-1, IgM), anti-CD36 (SMФ, $\operatorname{IgM}$ ), and anti-CD1b (WM25, IgG1) from Ylem (Avezzano, Italy); anti-CD86 (FUN-1, IgG1) was from PharMingen (San Diego, CA). Anti-FceRI (15-1, IgG1) was a kind gift from Dr. J.P. Kinet (Beth Israel Hospital, Boston, MA). FITC-conjugated anti-mouse $\operatorname{Ig~F}\left(\mathrm{ab}^{\prime}\right)_{2}$ was purchased from Silenus (Hawthorn, Australia). Control mouse IgG1 (C7-1) was a gift from Dr. E. Bonmassar (University of Tor Vergata, Rome, Italy).

Immunohistochemistry. Frozen 5- $\mu \mathrm{m}$ skin sections were fixed in acetone, permeabilized with $0.05 \%$ Triton X-100, and then incubated overnight at $4^{\circ} \mathrm{C}$ with appropriate dilution of anti-human GM-CSF $\mathrm{mAb}$ or control mouse IgG1, as described (15). Sections were stained

Table I. Clinical Features of Atopic Dermatitis Patients

\begin{tabular}{|c|c|c|c|c|c|}
\hline No., initials, sex & $\begin{array}{l}\text { Age } \\
\text { (yr) }\end{array}$ & $\begin{array}{c}\text { Age of } \\
\text { onset }\end{array}$ & $\begin{array}{c}\text { Extension } \\
\text { (percentage of } \\
\text { body surface) }\end{array}$ & Respiratory atopy & $\begin{array}{c}\text { Serum IgE } \\
(\mathrm{kU} / \mathrm{ml})\end{array}$ \\
\hline 1, AM, M & 29 & 2 & 35 & Asthma, rhinitis & $>2,000$ \\
\hline $2, \mathrm{FD}, \mathrm{M}$ & 38 & 5 & 40 & Asthma, rhinitis & 104 \\
\hline $3, \mathrm{EP}, \mathrm{F}$ & 15 & 3 & 60 & Rhinoconjunctivitis & 268 \\
\hline 4, MF, F & 31 & 16 & 30 & None & 90 \\
\hline $5, \mathrm{GG}, \mathrm{M}$ & 39 & 28 & 20 & None & 105 \\
\hline $6, \mathrm{MS}, \mathrm{F}$ & 16 & 8 & 40 & None & 531 \\
\hline 7, RG, F & 26 & 1 & 30 & Rhinitis & 671 \\
\hline $8, \mathrm{VP}, \mathrm{M}$ & 27 & 5 & 30 & None & 71 \\
\hline
\end{tabular}

according to an avidin-biotin-peroxidase technique (Vector Laboratories, Inc., Burlingame, CA), using 3-amino-9-ethylcarbazole as substrate. In competition experiments, anti-human GM-CSF mAb was incubated overnight with $10 \mu \mathrm{g} / \mathrm{ml} \mathrm{rhGM-CSF}$ at $4^{\circ} \mathrm{C}$ before application to tissue sections.

Keratinocyte cultures. Epidermal cell suspensions were prepared from suction blister roofs or from plastic surgery skin after separation of the epidermis from dermis with $0.5 \%$ dispase (Boehringer Mannheim, Mannheim, Germany). Briefly, epidermal sheets were rinsed on PBS, and then exposed to $0.25 \%$ trypsin (Biochrom KG, Berlin, Germany) for $30 \mathrm{~min}$, followed by $5 \mathrm{~min}$ of vigorous pipetting. After trypsin neutralization with equal volume of medium with $10 \%$ FBS (Delta Bioproducts, Johannesburg, South Africa), stratum corneum debris were removed using a 100- $\mu \mathrm{m}$ Falcon strainer (Becton Dickinson \& Co., Franklin Lakes, NJ). Isolated epidermal cells were seeded $\left(1.2-2 \times 10^{4} / \mathrm{cm}^{2}\right)$ on a feeder layer of irradiated 3T3/J2 fibroblasts $\left(2 \times 10^{4} / \mathrm{cm}^{2}\right)$ and cultured according to an optimized Rheinwald and Green culture technique (16). Culture medium consisted of a mixture of one part Ham F12 medium and three parts DME medium (Biochrom KG) supplemented with $10 \%$ FBS, $180 \mu \mathrm{M}$ adenine, $0.4 \mu \mathrm{g} / \mathrm{ml}$ hydrocortisone, $5 \mu \mathrm{g} / \mathrm{ml}$ insulin, $5 \mu \mathrm{g} / \mathrm{ml}$ apotransferrin, $0.1 \mathrm{nM}$ cholera toxin, $2 \mathrm{nM}$ triiodotyronine, $10 \mathrm{ng} / \mathrm{ml}$ human EGF (all Sigma Chemical Co.), $4 \mathrm{mM}$ glutamine, $100 \mathrm{U} / \mathrm{ml}$ penicillin, and $100 \mu \mathrm{g} / \mathrm{ml}$ streptomycin (all Biochrom KG). At $70-80 \%$ confluence, keratinocytes were detached with $0.05 \%$ trypsin $/ 0.02 \%$ EDTA, and then subcultured or frozen. Before being employed in functional assays, keratinocyte supernatants $(20 \mathrm{ml}$ each experiment) were dialyzed extensively against PBS (25 liters) at $4^{\circ} \mathrm{C}$.

ELISA assays. Cytokine quantitation was performed on supernatants collected after 48-h treatment of subconfluent second- or third-passage keratinocyte cultures carried out in $1.9 \mathrm{~cm}^{2}$ wells. Unless otherwise stated, during the assays Rheinwald medium was used in the absence of hydrocortisone and containing $0.1 \%$ BSA (Sigma Chemical Co.) instead of $10 \%$ FBS. GM-CSF Predicta ${ }^{\circledR}$ kit was purchased from Genzyme, Corp. and used according to the manufacturer's instructions. An ELISA reader (3550 UV; Bio-Rad Laboratories, Hercules, CA) was used. Keratinocyte cultures were carried out in triplicate for each condition and the data are represented as mean picograms or nanograms per $10^{6}$ cells \pm SD.

$R N A$ preparation and analysis. RNA was extracted with a modified guanidine isothiocyanate-acid phenol protocol (17) using Ultraspec $^{\mathrm{TM}}$ RNA Isolation System (Biotecx, Houston, TX). For reverse transcription PCR (RT-PCR) analysis, $1 \mu \mathrm{g}$ of total RNA was reverse transcribed with oligo-dT as primers (18), using a Perkin-Elmer RNA PCR kit (Roche Laboratories, Nutley, NJ), following the manufacturer's instructions. Amplifications of cDNA were performed in a final volume of $50 \mu \mathrm{l}$, with the thermal cycler GeneAmp PCR System 2400 (Perkin-Elmer Corp., Norwalk, CT). Synthetic oligonucleotides were used. As 5' GM-CSF primer: TGGCTGCAGAGCCTGCTGCTC, and as 3' GM-CSF primer: CAGTTCCAGTGACTCTTTCGGTGGAGCGTC. For GM-CSF cDNA amplification (expected cDNA product: $432 \mathrm{bp}$ ), 32 cycles were performed. Each cycle: $94^{\circ} \mathrm{C}$ for $1 \mathrm{~min}, 60^{\circ} \mathrm{C}$ for $1 \mathrm{~min}, 72^{\circ} \mathrm{C}$ for $1 \mathrm{~min}$. As $5^{\prime} \mathrm{G} 3 \mathrm{PDH}$ primer: TGAAGGTCGGAGTCAACGGATTTGGT, and as $3^{\prime}$ G3PDH primer: CATGTGGGCCATGAGGTCCACCAC. For G3PDH cDNA amplification (expected cDNA product: $983 \mathrm{bp}$ ), 26 cycles were performed. Each cycle: $94^{\circ} \mathrm{C}$ for $1 \mathrm{~min}, 60^{\circ} \mathrm{C}$ for $2 \mathrm{~min}$. Gels were stained with ethidium bromide and photographed with an ultraviolet transilluminator. For Northern blot experiments, RNA samples were fractionated on $1 \%$ agarose $/ 2 \%$ formaldehyde gels (Sigma Chemical Co.) and transferred onto Hybond-N membranes (Amersham International, Little Chalfont, UK) by capillarity. Blots were hybridized and washed under high stringency conditions (19) with a [ $\left.{ }^{32} \mathrm{P}\right] \mathrm{DNA}$ probe labeled by random priming with $\left[{ }^{32} \mathrm{P}\right] \mathrm{dCTP}$ (specific activity $3,000 \mathrm{Ci} /$ mmol; Amersham International) (20). The probe used for GM-CSF mRNA $(\sim 0.8 \mathrm{~kb})$ detection was kindly provided by Dr. S. Ferrari (University of Modena, Modena, Italy), and described elsewhere (21). As an internal control for the amount of RNA used, blots were 
hybridized using a probe corresponding to $28 \mathrm{~S}$ rRNA. The membranes were exposed to films at $-70^{\circ} \mathrm{C}$ for $2-4 \mathrm{~d}$.

PBMC proliferation test. PBMC were obtained by standard density gradient centrifugation of peripheral blood from healthy individuals. Unfractionated PBMC $\left(4 \times 10^{5}\right.$ cells/well $)$ were cultured in 96-well microculture plates in RPMI 1640 (Biochrom KG) supplemented with $10 \%$ FBS, $1 \mathrm{mM}$ sodium pyruvate, $0.1 \mathrm{mM}$ nonessential aminoacids, $2 \mathrm{mM}$ L-glutamine, $25 \mathrm{mM}$ Hepes, $100 \mathrm{U} / \mathrm{ml}$ penicillin, $100 \mu \mathrm{g} / \mathrm{ml}$ streptomycin (all Biochrom KG), and $0.05 \mathrm{mM}$ 2-mercaptoethanol (Merck, Darmstadt, Germany) (complete RPMI) at $37^{\circ} \mathrm{C}$ with $5 \% \mathrm{CO}_{2}$, in the presence of different concentrations of rhGM$\mathrm{CSF}$ or $50 \%$ (vol $/ \mathrm{vol}$ ) dialyzed keratinocyte supernatants. In some experiments, anti-GM-CSF mAb (final concentration $100 \mu \mathrm{g} / \mathrm{ml}$ ) was used. After $3 \mathrm{~d}$, cultures were pulsed with $5 \mu \mathrm{Ci} / \mathrm{ml}{ }^{3} \mathrm{H}$-thymidine (specific activity $82 \mathrm{Ci} / \mathrm{mmol}$, Amersham International) for $\sim 16 \mathrm{~h}$ at $37^{\circ} \mathrm{C}$, harvested onto fiber-coated 96 -well plates (Unifilter ${ }^{\mathrm{TM}}$ plates; Packard Instruments, Groningen, The Netherlands), and radioactivity measured in a $\beta$-counter (Topcount ${ }^{\mathrm{TM}}$; Packard Instruments). Results are given as mean counts per minute \pm SD of triplicate cultures. Statistical analysis was performed using the Student's $t$ test.

Adherent monocytes and monocyte-derived DC. DC were generated from adherent monocytes according to a defined protocol (22). Briefly, PBMC were allowed to adhere on tissue culture Petri dishes at $37^{\circ} \mathrm{C}$. After $2 \mathrm{~h}$, firmly adherent cells were recovered and depleted of $\mathrm{CD}_{2}^{+}, \mathrm{CD}_{16}{ }^{+}$, and $\mathrm{CD} 19^{+}$cells by incubation with immunomagnetic beads coated with specific mAbs (Dynabeads M450; Dynal, Oslo, Norway). Remaining cells ( $>90 \% \mathrm{CD}^{+}{ }^{+}$) were used immediately or cultured at $10^{6} / \mathrm{ml}$ in complete RPMI added to $200 \mathrm{ng} / \mathrm{ml}$ rhGM-CSF and $200 \mathrm{U} / \mathrm{ml}$ rhIL- 4 at $37^{\circ} \mathrm{C}$ with $5 \% \mathrm{CO}_{2}$. In experiments testing keratinocyte-conditioned medium, keratinocyte supernatants were dialyzed and either used at $50 \%$ (vol/vol) or 20 -fold concentrated after dialysis, and in this case used at $15 \%$ (vol $/ \mathrm{vol}$ ) final culture medium. Supernatant concentration was performed using Centriprep-3 (membrane cutoff $=3,000$ ) concentrators (Amicon, Inc., Beverly, MA). Culture medium was replaced after 3-4 d and DC were used after 6-7 d of culture.

Cell suspension immunolabeling. Adherent monocytes or monocyte-derived DC were incubated for 30 min with PBS containing 5\% human serum, and then stained on ice with FITC-conjugated mAbs or unconjugated primary mAbs followed by FITC-conjugated antimouse Ig. In control samples, the primary mAb was omitted or substituted with a matched isotype control. Cells were evaluated with a FACScan ${ }^{\circledR}$ equipped with Cell Quest software (Becton Dickinson \& Co., Mountain View, CA).

Mixed leukocyte reaction. Freshly prepared adherent monocytes, or monocytes treated with cytokines or concentrated keratinocyteconditioned medium, were cocultured in 96-well microculture plates together with $2 \times 10^{5}$ cells/well allogeneic T lymphocytes. T lymphocytes were purified from PBMC by depletion of adherent cells, followed by treatment with a mixture of anti-HLA-DR, anti-CD19, and anti-CD16 mAbs and immunomagnetic depletion. After two rounds of bead depletion, the purity of T cells was $>95 \%$. Culture medium consisted of complete RPMI containing 5\% autologous human serum. After $2-5 \mathrm{~d}$, cocultures were pulsed with $5 \mu \mathrm{Ci} / \mathrm{ml}^{3} \mathrm{H}$-thymidine for $\sim 16 \mathrm{~h}$ at $37^{\circ} \mathrm{C}$, and incorporated radioactivity measured as described above. Results are given as mean counts per minute \pm SD of triplicate cultures.

\section{Results}

Increase in immunoreactive GM-CSF in lesional skin of $A D$ patients. Erythematous chronic lesions and nonlesional skin of three AD patients were evaluated for GM-CSF immunoreactivity. Both the epidermal and dermal compartments of lesional skin were strongly reactive for GM-CSF. In the epidermis, keratinocytes showed uniformly high cytoplasmic reactivity (Fig. 1). Intense staining with a cytoplasmic pattern was ob- served in the perivascular inflammatory cell infiltrate and in cells of the upper part of the dermis, with individual inflammatory cells staining more strongly than keratinocytes, in agreement with the results of previous in situ hybridization studies (23). Nonlesional skin of AD patients displayed very limited inflammatory infiltrate and epidermal changes. These sections showed faint epidermal GM-CSF reactivity (Fig. 1) and scattered positive cells in the dermis, with a pattern similar to that of normal skin from nonatopic controls (not shown). Staining of lesional and nonlesional skin of AD patients with the absorbed anti-GM-CSF mAb showed only trace reactivity.

The observation of intense GM-CSF immunoreactivity in epidermis of lesional skin led us to study the regulation of GM-CSF production in keratinocytes from $\mathrm{AD}$ patients in vitro.

Keratinocytes cultured from AD patients show enhanced production of GM-CSF compared with keratinocytes from nonatopic controls. Keratinocyte cultures were established from normal-appearing skin of AD patients and nonatopic controls,
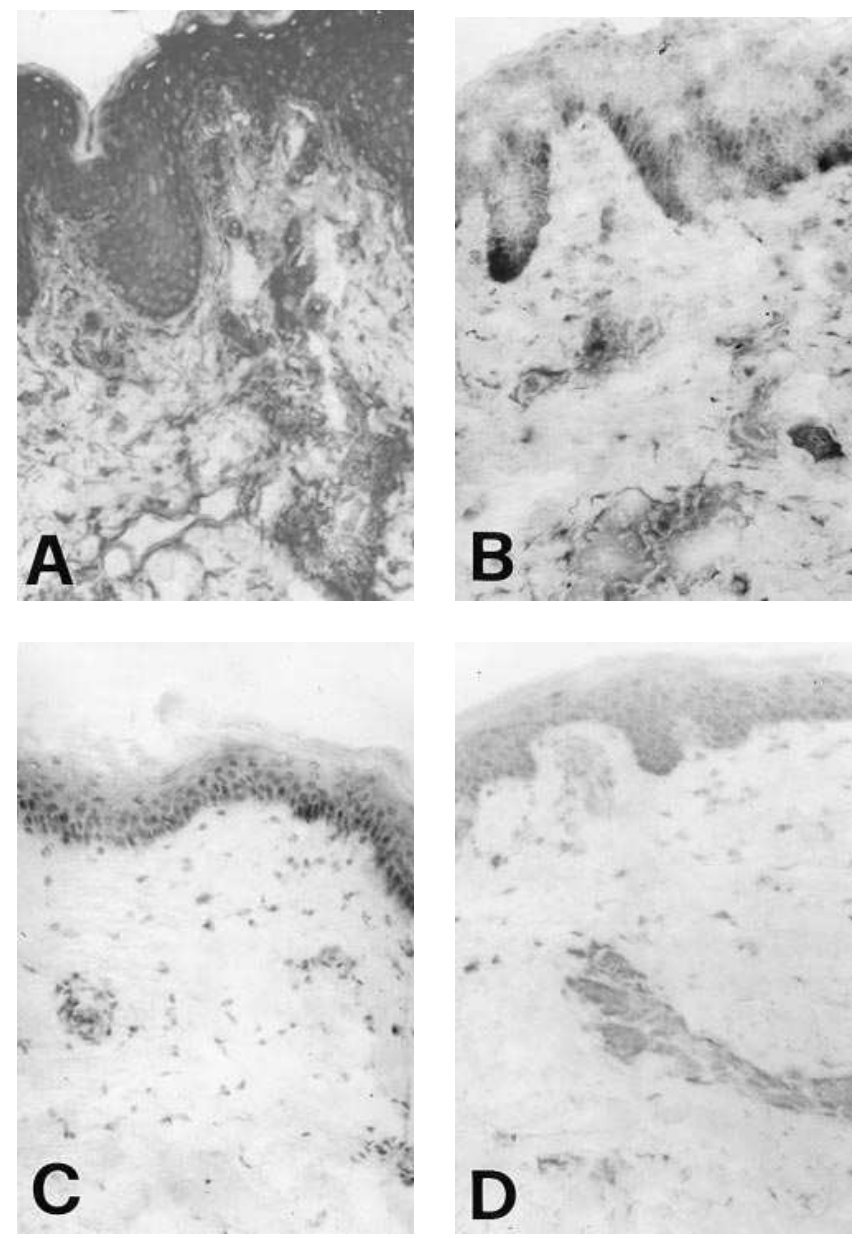

Figure 1. Increased immunoreactive GM-CSF in AD lesional skin. $(A)$ Lesional AD skin shows intense cytoplasmic staining for GMCSF in both epidermis and dermal infiltrate. $(B)$ Staining intensity is markedly diminished when anti-GM-CSF $\mathrm{mAb}$ is preincubated with rhGM-CSF. (C) Nonlesional skin shows limited GM-CSF immunoreactivity in the epidermis and in a few dermal cells, which is reduced when a neutralized anti-GM-CSF $\mathrm{mAb}$ is used $(D)$. $A-D$ show lesional and nonlesional skin obtained from $A D$ patient No. 2. Original magnification $200 \times$. 
and evaluated for GM-CSF release in the supernatants. Keratinocytes were used at second or third passage to avoid any possible influence from medications applied to the skin and eliminate the presence of any contaminating cells; (i.e., passenger leukocytes). Fig. $2 A$ shows that spontaneous GM-CSF release by untreated keratinocyte cultures prepared from control individuals was uniformly low. In contrast, keratinocytes from seven of eight $\mathrm{AD}$ patients released substantial amounts of GM-CSF, 3-25-fold higher than control keratinocytes. When stimulated with $10 \mathrm{ng} / \mathrm{ml}$ PMA for $48 \mathrm{~h}$, a dramatic increase in GM-CSF release was observed in supernatants of keratinocytes from both nonatopic donors and AD patients (Fig. 2 $B$ ). However, keratinocyte cultures prepared from seven of eight AD patients released much higher levels of GM-CSF than control keratinocytes. Because primary cultures from AD patients were prepared from suction blister epidermis, whereas primary cultures from the first four control subjects were obtained from surgery skin, we asked whether different GM-CSF release was due to differences in skin donor site or in the selection of distinct proliferating keratinocyte populations (e.g., nonfollicular vs. follicular keratinocytes). Therefore, two additional nonatopic controls (No. 5 and 6) were studied whose primary cultures were established from a skin site and with a procedure (suction blister) identical to those employed for AD patients. Yet, control keratinocyte cultures produced lower amounts of GM-CSF. In addition, increased production of GM-CSF by AD keratinocytes was also observed when cells were plated at different densities (not shown).

RT-PCR analysis showed higher constitutive as well as

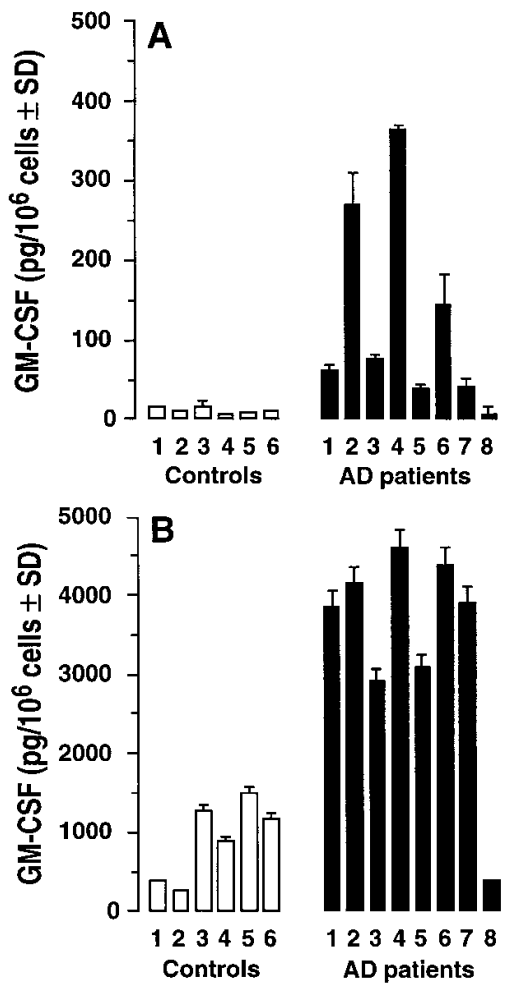

Figure 2. Keratinocytes cultured from AD patients show enhanced spontaneous $(A)$ and PMA-induced $(B)$ release of GM-CSF compared with keratinocytes cultured from nonatopic controls. $(A)$ Spontaneous GM-CSF release in the supernatants of keratinocytes from control donors ( $n=6$; white bars) is significantly lower than that from keratinocytes of AD patients $(n=8$; black bars). (B) When stimulated with $10 \mathrm{ng} /$ ml PMA, augmented GM-CSF release is observed in keratinocyte cultures from both nonatopic subjects and $\mathrm{AD}$ patients, but the amounts are much higher in AD keratinocyte cultures. GM-CSF quantitation was performed by ELISA on supernatants collected after $48 \mathrm{~h}$ of subconfluent third-passage keratinocyte cultures. During the assay, Rheinwald-Green medium was used in the absence of hydrocortisone, and contained $0.1 \%$ BSA instead of $10 \%$ FBS.
PMA-induced GM-CSF gene expression in AD-derived keratinocytes compared with healthy control keratinocytes (Fig. 3 $A$ ), suggesting that a dysregulation of GM-CSF production by AD keratinocytes is present at a pretranslational level. Northern blot analysis confirmed the presence of a higher expression of GM-CSF mRNA in stimulated AD keratinocytes after $12 \mathrm{~h}$ stimulation with $10 \mathrm{ng} / \mathrm{ml}$ PMA, whereas untreated nonatopic as well as atopic keratinocytes did not give visible bands in the experimental conditions employed (Fig. $3 \mathrm{~B}$ ). In the above mentioned experiments, keratinocytes were cultured in medium without hydrocortisone, which is known to suppress GMCSF production by keratinocytes (24). The addition of hydrocortisone $(0.4 \mu \mathrm{g} / \mathrm{ml})$ to the culture medium was capable of downregulating GM-CSF gene expression (Fig. 4) and markedly lowering GM-CSF protein release in keratinocytes from both AD patients and controls. For example, hydrocortisone decreased spontaneous GM-CSF release from 11.25 \pm 1.5 to
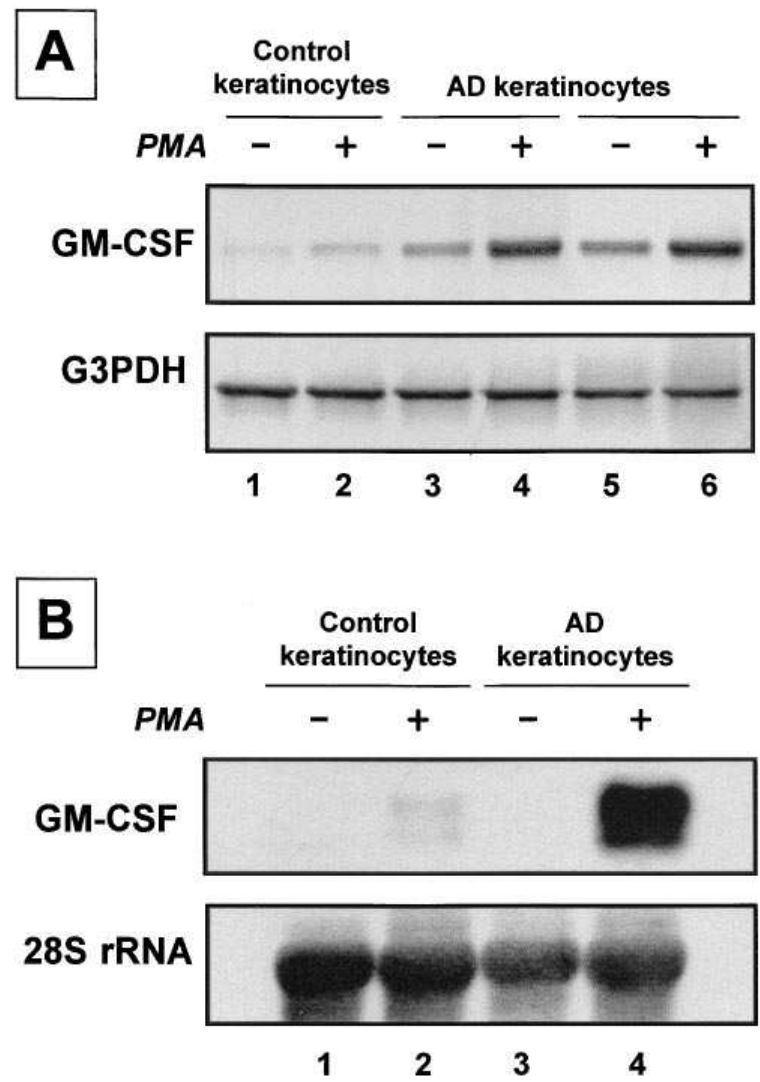

Figure 3. Keratinocytes cultured from AD patients show enhanced constitutive and PMA-induced GM-CSF gene expression compared with keratinocytes cultured from control subjects. $(A)$ RT-PCR analysis: cells were $80-90 \%$ confluent and cultured for the last $48 \mathrm{~h}$ in medium without hydrocortisone and containing $0.1 \%$ BSA. Total RNA was extracted from control case 1 (lanes 1 and 2), and AD cases 1 (lanes 3 and 4 ) and 4 (lanes 5 and 6 ). $1 \mu \mathrm{g}$ RNA was used for retrotranscription. Product size: GM-CSF, 432 bp. G3PDH, 983 bp. (B) Northern blot analysis: total RNA $(10 \mu \mathrm{g} / \mathrm{ml})$ was extracted from keratinocyte cultures prepared from control case 5 (lanes 1 and 2) and AD case 6 (lanes 3 and 4 ) after a 12-h treatment. As an internal control for the amount of RNA used, blots were hybridized using a probe corresponding to $28 \mathrm{~S}$ rRNA $(\sim 5.1 \mathrm{~kb})$. GM-CSF mRNA $(\sim 0.8 \mathrm{~kb})$ was not detectable in nonstimulated keratinocytes. 

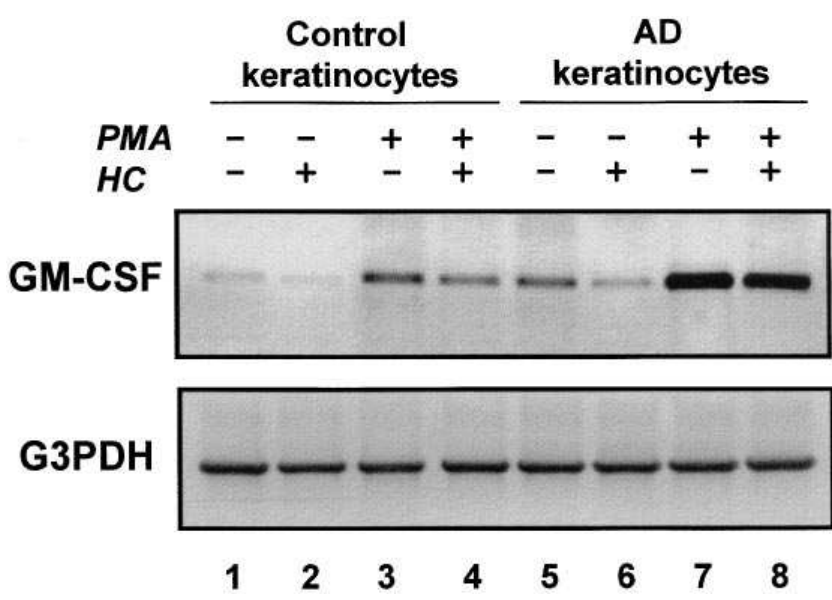

Figure 4. Hydrocortisone (HC) downregulates GM-CSF gene expression in keratinocytes from both $\mathrm{AD}$ patients and control individuals. RT-PCR analysis was performed on total RNA extracted from keratinocytes of control case 2 (lanes 1 and 4 ) and AD case 3 (lanes 5 and 8 ), after 48 -h treatments.

$0.75 \pm 0.5 \mathrm{pg} / 10^{6}$ cells $/ 48 \mathrm{~h}$ in control case No. 1 , and from $75.5 \pm 5.5$ to $21.25 \pm 5.25 \mathrm{pg} / 10^{6}$ cells $/ 48 \mathrm{~h}$ in AD patient No. 3 . In PMA-stimulated keratinocytes, hydrocortisone reduced GM-CSF release from $250 \pm 25$ to $117.5 \pm 14 \mathrm{pg} / 10^{6}$ cells $/ 48 \mathrm{~h}$ in control case No. 1 , and from $4,142 \pm 192.5$ to $1,905 \pm 87.5 \mathrm{pg} / 10^{6}$ cells $/ 48 \mathrm{~h}$ in $\mathrm{AD}$ patient No. 3.

Other stimuli, such as IL-1 (24) and bacterial products (25), known for their potential to stimulate GM-CSF secretion by keratinocytes, have been tested. LPS, lipoteichoic acid, and staphylococcal enterotoxin B did not increase GM-CSF release, either in healthy or AD keratinocytes cultures. On the other hand, IL-1 $\alpha$ induced an increase in GM-CSF release that was much higher in cultures of AD keratinocytes compared with control keratinocytes (Fig. 5).

Supernatant from AD keratinocytes stimulates proliferation of PBMC and supports immunophenotypical and functional maturation of peripheral blood precursors towards the DC lineage. GM-CSF is an efficient proliferatory stimulus for PBMC (26). Therefore, we tested whether supernatants from keratinocytes could promote PBMC proliferation. In Fig. 6, proliferation data for PBMC cultured for $72 \mathrm{~h}$ in complete RPMI in the presence of different concentrations of rhGM-CSF (Fig. 6, inset), or dialyzed keratinocyte supernatants of untreated or PMA-stimulated keratinocytes, are reported. Supernatants of unstimulated keratinocytes from AD patients could induce a PBMC-proliferative response significantly higher than that obtained with supernatants of control keratinocytes $(P<0.003)$. Conditioned medium from PMA-stimulated keratinocytes promoted increased PBMC proliferation, again with augmented response when supernatants of AD keratinocytes were used $(P<0.003)$. PBMC proliferation due to keratinocyte supernatants could be specifically and totally abrogated when an anti-GM-CSF mAb, but not control mouse IgG1, was added to the culture, confirming the essential role of GM-CSF for this effect.

Recently, it has been shown that adherent peripheral blood monocytes $\left(\mathrm{CD} 14^{+}, \mathrm{CD}^{-} \mathrm{a}^{-}\right)$can be driven to differentiate into DC when cultured for a few days in the presence of rhGMCSF and rhIL-4 (22). Thus, in the following experiments, we sought to determine whether AD keratinocyte-conditioned medium could support differentiation of DC from monocytes. Preliminary experiments using 30-50\% (vol/vol) PMA-treated keratinocyte-conditioned medium failed to show any significant change in morphology or immunophenotype of treated monocytes. Subsequently, supernatants from PMA-stimulated AD keratinocytes were 20 -fold concentrated and used at $15 \%$ (vol/vol) final culture medium together with $200 \mathrm{U} / \mathrm{ml}$ rhIL-4. GM-CSF in the concentrated keratinocyte-conditioned medium was typically $2-4 \mathrm{ng} / \mathrm{ml}$, as determined by ELISA. Morphologically, monocytes cultured in the presence of concentrated AD keratinocyte supernatant formed loosely adherent colonies and developed a typical dendritic morphology with thin cytoplasmic projections; results are undistinguishable from DC generated in the presence of rhGM-CSF (Fig. 7, $A$ and $B$ ). Addition of rhIL-4 alone or of anti-GM-CSF $m A b$ to monocytes cultured with supernatant of PMA-stimulated keratinocytes resulted in poor cell survival after a few days (Fig. 7, $C$ and $D$ ). Similarly, monocyte cultures supplemented with supernatant from nonatopic control keratinocytes could not be carried out because of the high mortality rate after 2-3 d (data not shown). In Fig. 8, the immunophenotypical profiles of freshly prepared adherent monocytes (Fig. $8 A$ ), of DC generated from monocytes after $7 \mathrm{~d}$ of culture with rhGM-CSF and rhIL-4 (Fig. $8 \mathrm{~B}$ ), and of cells obtained after $7 \mathrm{~d}$ of culture in the presence of concentrated supernatant from PMA-treated AD keratinocytes and rhIL-4 (Fig. $8 \mathrm{C}$ ), are compared. Conditioned medium from PMA-treated AD keratinocyte cultures induced increased expression of HLA-DR, CD1a, and CD1b, and strongly decreased CD36 and CD14 expression. In contrast, no effects were observed in the expression of CD80 and CD86 costimulatory molecules as well as of CD23 and FceRI.

Functionally, DC obtained using conditioned medium from PMA-treated AD keratinocyte cultures were stronger stimulators of naive allogeneic $\mathrm{T}$ cells compared with adherent monocytes, even though less potent than DC generated with rhGMCSF (Fig. 9).

\section{Discussion}

The results presented here show a strong immunoreactivity for GM-CSF in lesional AD skin with intense staining of both the inflammatory infiltrate and keratinocytes, suggesting that GMCSF is over-produced by keratinocytes in AD in vivo. Nonlesional skin of AD patients showed faint epidermal GM-CSF

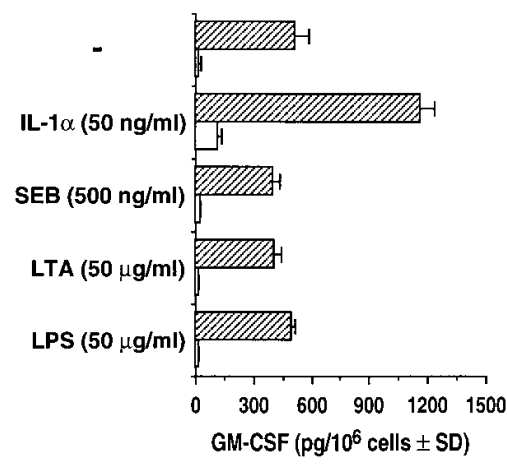

Figure 5. IL-1 $\alpha$, but not staphylococcal enterotoxin B $(S E B)$, lipoteichoic acid (LTA), or lipopolysaccharide (LPS), stimulates GMCSF release from cultured keratinocytes. Keratinocytes from the AD patient (case 3 , striped bars) secrete a higher quantity of GMCSF compared with keratinocytes from nonatopic control (control case 2, white bars). 


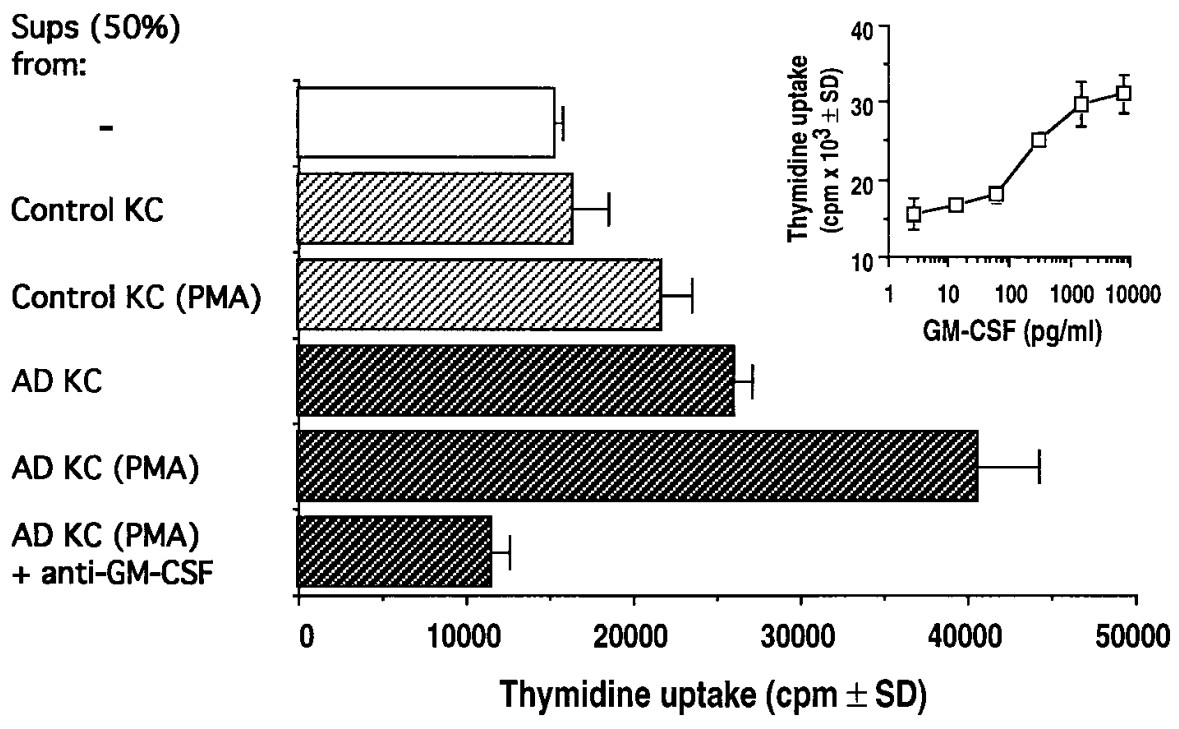

Figure 6. Supernatants from AD keratinocyte cultures potently stimulate PBMC proliferation. Unfractionated PBMC were cultured for $72 \mathrm{~h}$ in the presence of dialyzed keratinocyte-conditioned medium. Supernatants (Sups) from unstimulated or PMA-stimulated control keratinocytes did not promote significant PBMC proliferation. In contrast, supernatants from unstimulated or PMA-stimulated AD keratinocytes enhanced PBMC proliferation significantly $(P<0.003)$. Anti-GM-CSF $\mathrm{mAb}(100 \mu \mathrm{g} / \mathrm{ml})$ could abrogate completely the stimulating activity of PMAtreated $\mathrm{AD}$ keratinocyte supernatants on PBMC proliferation. PBMC-proliferative response to rhGM-CSF is shown (inset). reactivity, and a general pattern that appeared undistinguishable from that of normal skin from nonatopic controls. By contrast, in vitro studies show that epidermal keratinocytes from most AD patients spontaneously synthesize and release increased quantities of GM-CSF, as compared with keratinocytes cultured from nonatopic controls. This difference between in vivo and in vitro findings in basal expression of GM-CSF is possibly a consequence of the different sensitivities of the techniques employed. On the other hand, culture conditions could provide nonspecific stimuli to cells, with atopic keratinocytes appearing more susceptible than nonatopic keratinocytes. PMA was a potent stimulus for induction of GM-CSF gene expression as well as protein release, with keratinocytes from seven of eight $\mathrm{AD}$ patients showing exaggerated responses. PMA is a potent activator of phospholipid- and $\mathrm{Ca}^{++}-$ dependent protein kinase $\mathrm{C}$ and mimics the action of diacylglycerols. We could demonstrate that, similar to what is seen with PMA, synthetic 1,2-dioctanoyl-sn-glycerol promoted significantly higher GM-CSF secretion from AD keratinocytes when compared with healthy controls (data not shown). Also, IL-1 $\alpha$ was able to induce enhanced GM-CSF release from cultured keratinocytes, as previously published (24), AD keratinocytes were still producing significantly higher levels of this growth factor when compared with healthy controls. AD skin is characterized by impaired epidermal permeability barrier, and this may be causally linked to skin inflammation since acute barrier perturbation can stimulate production of cytokines, including IL- $1 \alpha$ and GM-CSF, in both mice and humans $(15,27,28)$. Bacterial infections are well recognized triggers of AD flares (1), but bacterial products (LPS, lipoteichoic acid, or esotoxins) did not increase GM-CSF release over basal levels in either AD or control keratinocytes.

Quite interestingly, our data on an enhanced production of GM-CSF extend to epidermal cells what other researchers have variously reported for atopic diseases of the respiratory tract. Cell cultures obtained from bronchial biopsies of atopic asthmatics were found to release significantly higher amounts of GM-CSF when compared with controls, and the epithelial origin of the growth factor has been demonstrated (10). Moreover, PBMC, T cells, and bronchoalveolar lavage cells from asthmatic patients have been shown to spontaneously release significantly higher concentrations of GM-CSF into the culture medium, when compared with cells from control subjects (29, 30). In the case of AD, Bratton et al. found that PBMC from AD patients produce significantly higher levels of GM-CSF compared with PBMC from healthy controls (23). In the same study, they also noticed by in situ hybridization that skin biopsies from chronic AD patients presented a significantly greater number of GM-CSF mRNA-positive dermal as well as epidermal cells compared with healthy controls, and proposed that, in addition to infiltrating inflammatory cells, keratinocytes
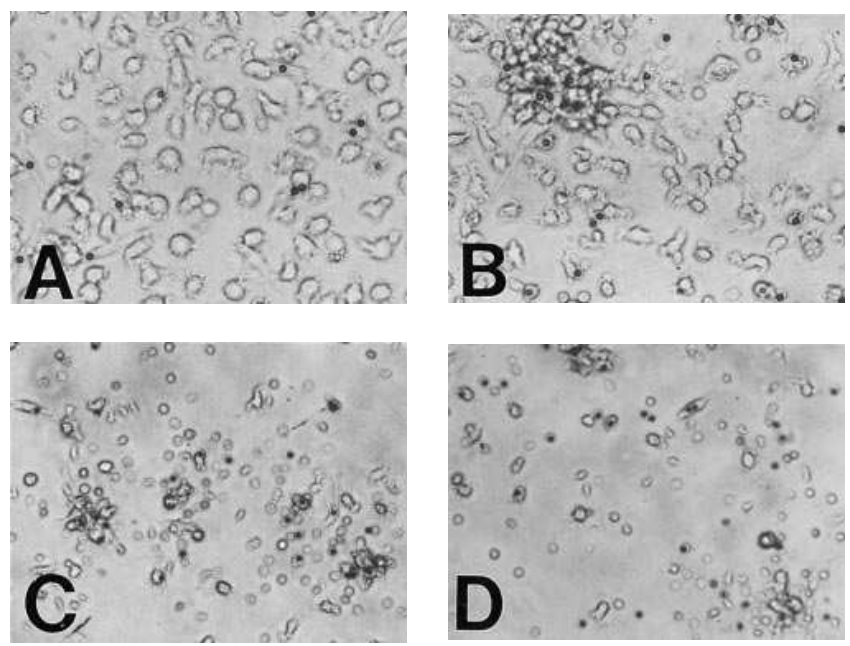

Figure 7. Development of DC morphology in monocytes exposed to supernatant from PMA-stimulated AD keratinocytes and rhIL-4. $(A)$ Adherent monocytes $\left(>90 \% \mathrm{CD}^{+} 4^{+}\right)$cultured for $7 \mathrm{~d}$ with rhIL-4 and rhGM-CSF. (B) Adherent monocytes cultured for $7 \mathrm{~d}$ in the presence of rhIL-4 and concentrated supernatant from PMA-stimulated keratinocyte cultures. $(C)$ Adherent monocytes $\left(>90 \% \mathrm{CD}^{+} 4^{+}\right)$cultured for $7 \mathrm{~d}$ with rhIL-4 alone. $(D)$ Same condition as in $B$, but in the presence of anti-GM-CSF mAb $(100 \mu \mathrm{g} / \mathrm{ml})$. Original magnification $320 \times$. 
A
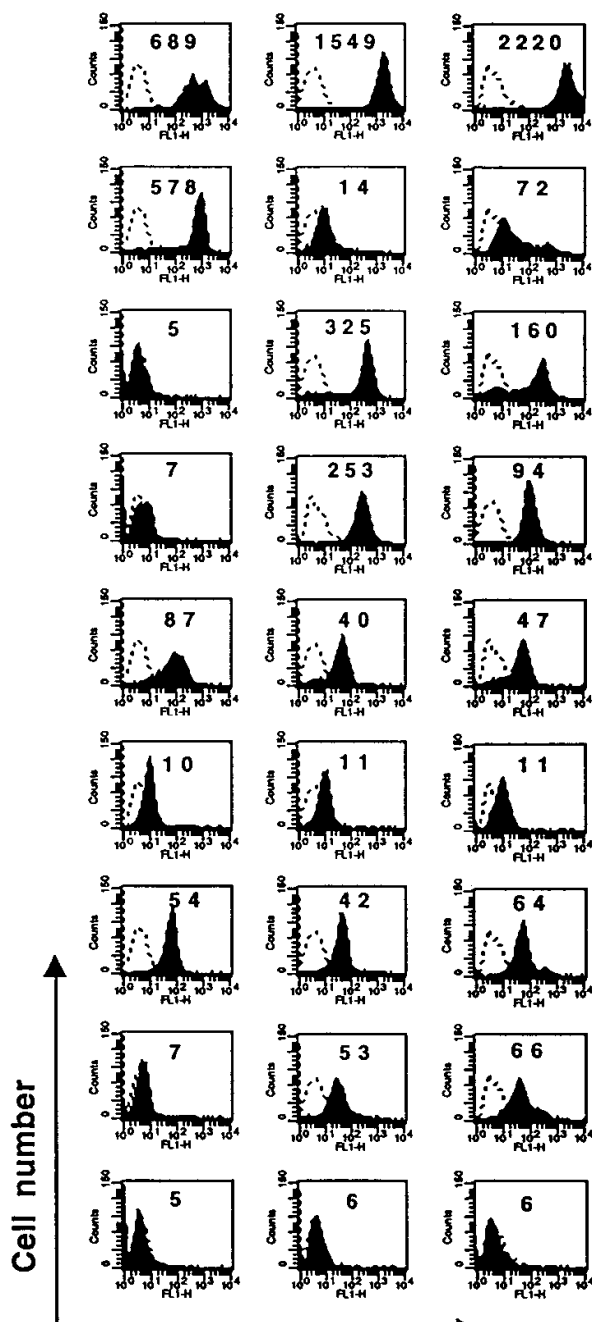

HLA-DR
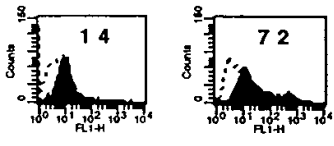

CD14
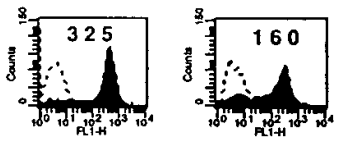

CD1a
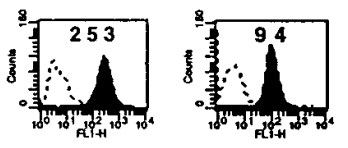

CD1b
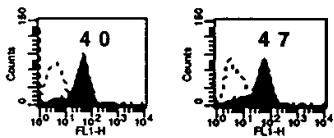

CD36
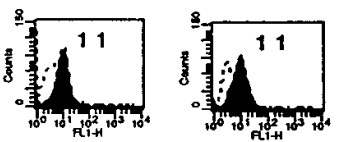

CD80
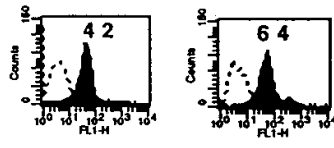

CD86
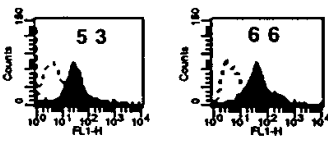

CD23

Fluorescence intensity

Figure 8. Supernatant from PMA-stimulated AD keratinocyte cultures drives immunophenotypic differentiation of monocytes into DC. Adherent monocytes depleted of $\mathrm{CD} 19^{+}, \mathrm{CD}^{+}$, and $\mathrm{CD} 16^{+}$ cells $\left(>90 \% \mathrm{CD}^{+} 4^{+}\right)$were analyzed immediately $(A)$ or cultured for $7 \mathrm{~d}$ with rhIL-4 and rhGM-CSF $(B)$, or cultured for $7 \mathrm{~d}$ in the presence of concentrated supernatant from PMA-stimulated keratinocytes (AD case 4) and rhIL-4 (C).

could abundantly contribute to this scenario. Our results confirm these findings at the protein level and emphasize the primary role of keratinocytes in GM-CSF overproduction in AD skin. The reason(s) for enhanced GM-CSF production by AD keratinocytes and other cells in atopics is unknown. Elevated serum IgE level has been associated with polymorphisms in chromosome 5q31.1, which contains the coding regions for several cytokines potentially implicated in allergic immune responses, including IL-4 and GM-CSF (31). It is thus possible that in $\mathrm{AD}$ as well as in other atopic diseases, there is a functional polymorphism in GM-CSF coding and/or regulatory region, in turn responsible for a dysregulated synthesis of the cytokine.
An interesting observation in our study was that conditioned medium from AD keratinocyte cultures was an efficient proliferatory stimulus for cultured PBMC, an effect that could be abrogated by the use of anti-GM-CSF mAb. Moreover, supernatants from PMA-stimulated AD keratinocyte cultures, together with exogenous rhIL-4, could efficiently support maturation of monocytes into cells that presented morphological, immunophenotypical, and functional properties of DC (22). Together with IL-3, IL-4, and IL-5, GM-CSF is released at the site of antigen-specific challenge in atopic patients, both at cutaneous $(32,33)$ and respiratory levels $(34,35)$, and works as a potent stimulus for recruitment, proliferation, and activation of monocytes, basophils, and eosinophils. A higher release of GM-CSF can thus fully explain the nature and intensity of the inflammatory infiltrate found in the tissues involved in atopic diseases. In particular, GM-CSF was recently proved to be important for increased survival of AD monocytes in culture by reducing the spontaneous apoptotic death of these cells (23). Furthermore, GM-CSF released by keratinocytes was shown to induce proliferation of cells of the macrophage lineage (36), which are among the predominant inflammatory cells in chronic AD lesions (1). Most importantly, however, it has been suggested that this growth factor can considerably contribute to $\mathrm{DC} / \mathrm{LC}$ recruitment into tissues, as well as to their survival and maturation into highly efficient antigen-presenting cells. GM-CSF is recognized as a necessary factor for differentiation of DC precursors in both human and mouse systems in vitro (37). In contrast to myeloid DC, the development of DC of lymphoid lineage has been recently shown to be independent of GM-CSF in the mouse (38). GM-CSF is a primary stimulus for recruitment and survival, as well as activation of LC, both in vitro and in vivo (39-42). A major change after intradermal injection of GM-CSF was the progressive accumulation of $\mathrm{CD} \mathrm{a}^{+}$, Birbeck granule-positive cells in the dermis (43). Similarly, a close correlation has been demonstrated between the level of production of GM-CSF by human bronchial epithelium and the number of $\mathrm{CD}^{2} \mathrm{a}^{+} \mathrm{LC}$ infiltrating this tissue, suggesting that the local production of this cytokine plays an important role in determining the distribution and number of DC/LC (44). In agreement with the increased production of GM-CSF by keratinocytes, LC and DC are increased in number and they are in an activated state in $\mathrm{AD}$ lesional skin $(2,3$,

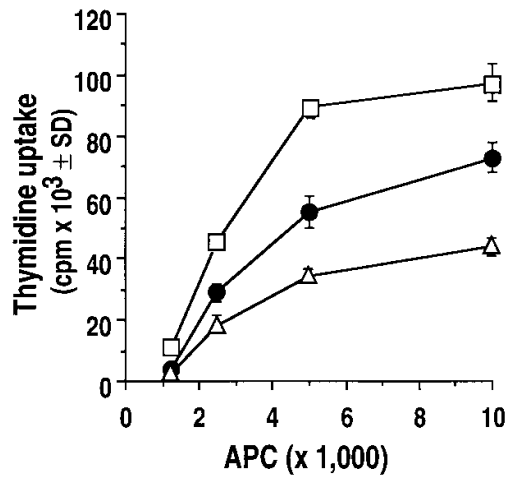

Figure 9. Supernatants from $\mathrm{AD}$ keratinocyte cultures induce functional maturation of monocytes. Graded numbers of antigen-presenting cells (prepared as described in Fig. 6) were cocultured with purified naive allogeneic $T$ cells $\left(150 \times 10^{3}\right.$ cells/well) for $5 \mathrm{~d} . \triangle$, Adherent monocytes; -, adherent monocytes cultured for $7 \mathrm{~d}$ in the

presence of concentrated supernatant from PMA-stimulated keratinocyte cultures and rhIL-4; $\square$, adherent monocytes cultured for $7 \mathrm{~d}$ in the presence of rhIL-4 and rhGM-CSF. Proliferation of T cells alone was $800 \pm 120 \mathrm{cpm}$. 
7). In addition, $A D$ epidermis is infiltrated by unique DC having a phenotype intermediate between DC and monocytes $\left(\mathrm{CD}^{+} \mathrm{a}^{+}, \mathrm{CD} \mathrm{b}^{+}, \mathrm{CD} 36^{+}\right)$and with enhanced antigen presenting capacity $(4,5)$. Peripheral blood monocytes treated with AD keratinocyte-conditioned medium and rhIL-4 strongly resemble these cells in both phenotype and function. We therefore postulate that, as monocytes pass through the milieu of $\mathrm{AD}$ skin, they are induced to differentiate into DC by GMCSF provided by activated keratinocytes and IL-4 released by dermal mast cells (45). In this way, increased concentrations of GM-CSF at the skin level could explain the persistent infiltration of monocytes and activated DC. Finally, GM-CSF is to date the only cytokine that has been shown to be mitogenic for human keratinocytes, both in vivo $(43,46)$ and in vitro (47), thus representing a favored autocrine factor responsible for the epidermal hyperplasia observed in chronic AD.

Glucocorticoids are among the most effective and frequently used treatments for atopic diseases, both of the skin and the airways. Although the mechanisms underneath their potent antiinflammatory activity are multiple, the clinical improvement is always associated with a decrease in the presence of inflammatory cells at the lesion sites. In particular, a correlation between therapeutic efficacy of inhaled corticosteroids and the decrease in the number of DC populating the bronchial mucosa of atopic asthmatic patients has been established, confirming the involvement of DC in asthmatic immune inflammation (10). Thus it seems reasonable to propose epithelial cells as a major target of glucocorticoid activity, since these drugs downregulate the expression of signals implicated in the local attraction and activation of a variety of inflammatory cells $(48,49)$.

\section{Acknowledgments}

The authors thank D. Mei for her excellent technical assistance, Dr. J.P. Kinet for the gift of 15-1 mAb, and Dr. S. Ferrari for the GMCSF probe.

This work was supported by grants from the Italian Ministry of Health (Progetto di Ricerca Finalizzata) and from the Istituto Superiore di Sanità (Progetto AIDS, grant 9403-54).

\section{References}

1. Leung, D.Y.M. 1995. Atopic dermatitis: the skin as a window into the pathogenesis of chronic allergic diseases. J. Allergy Clin. Immunol. 96:302-318.

2. Bos, J.D., I.D. van Garderen, S.R. Krieg, and L.W. Poulter. 1986. Different in situ distribution patterns of dendritic cells having Langerhans $\left(\mathrm{T}^{+}\right)$and interdigitating $\left(\mathrm{RFD}^{+}\right)$cell immunophenotype in psoriasis, atopic dermatitis and other inflammatory dermatoses. J. Invest. Dermatol. 87:358-361.

3. Bieber, T., J. Ring, and O. Braun-Falco. 1988. Comparison of different methods for enumeration of Langerhans cells in vertical cryosections of human skin. Br. J. Dermatol. 118:385-392.

4. Taylor, R.S., O. Baadsgaard, C. Hammerberg, and K.D. Cooper. 1991. Hyperstimulatory $\mathrm{CD}_{1} \mathrm{a}^{+} \mathrm{CD} 1 \mathrm{~b}^{+} \mathrm{CD} 36^{+}$Langerhans cells are responsible for increased autologous $\mathrm{T}$ lymphocyte reactivity to lesional epidermal cells of patients with atopic dermatitis. J. Immunol. 147:3794-3802.

5. Wollenberg, A., S. Kraft, D. Hanau, and T. Bieber. 1996. Immunomorphological and ultrastructural characterization of Langerhans cells and a novel, inflammatory dendritic epidermal cells (IDEC) population in lesional skin of atopic eczema. J. Invest. Dermatol. 106:446-453.

6. Steinman, R.M. 1991. The dendritic cell system and its role in immunogenicity. Annu. Rev. Immunol. 9:271-296.

7. Ohki, O., H. Yokozeki, I. Katayama, M. Azuma, K. Okumura, and K. Nishioka. 1996. Expression and function of CD80 (B7/B7-1) and CD86 (B70/ B7-2) in atopic dermatitis. J. Invest. Dermatol. 106:880a. (Abstr.)

8. Klubal, R., B. Osterhoff, B. Wang, J.-P. Kinet, D. Maurer, and G. Stingl. 1997. The high-affinity receptor for IgE is the predominant IgE-binding structure in lesional skin of atopic dermatitis patients. J. Invest. Dermatol. 108:336-
342

9. Mudde, G.C., F.C. Van Reijsen, G.J. Boland, G.C. de Gast, P.L.B Bruijnzeel, and C.A.F.M. Bruijnzeel-Koomen. 1990. Allergen presentation by epidermal Langerhans cells from patients with atopic dermatitis is mediated by IgE. Immunology. 69:335-341.

10. Bellini, A., E. Vittori, M. Marini, V. Ackerman, and S. Mattoli. 1993. Intraepithelial dendritic cells and selective activation of Th2-like lymphocytes in patients with atopic asthma. Chest. 103:997-1005.

11. Möller, G.M., S.E. Overbeek, C.G. van Helden-Meeuwsen, J. M.W. van Haarst, E.P. Prens, P.G. Mulder, D.S. Postma, and H.C. Hoogsteden. 1996. Increased numbers of dendritic cells in the bronchial mucosa of atopic asthmatic patients: downregulation by inhaled corticosteroids. Clin. Exp. Allergy. 26:517524.

12. Hamid, Q., M. Boguniewicz, and D.Y.M. Leung. 1994. Differential in situ cytokine gene expression in acute versus chronic atopic dermatitis. J. Clin. Invest. 94:870-876.

13. Pastore, S., A. Cavani, and G. Girolomoni. 1996. Epidermal cytokine and neuronal peptide modulation of contact hypersensitivity reactions. Immunopharmacology. 31:117-130.

14. Hanifin, J.M., and G. Rajka. 1980. Diagnostic features of atopic dermatitis. Acta Dermato-Venereol. Suppl. 92:44-47.

15. Wood, L.C., P.M. Elias, C. Calhoun, J.C. Tsai, C. Grunfeld, and K.R. Feingold. 1996. Barrier disruption stimulates interleukin-1 $\alpha$ expression and release from a pre-formed pool in murine epidermis. J. Invest. Dermatol. 106:397403.

16. Rheinwald, J.G. 1989. Methods for clonal growth and serial cultivation of normal human epidermal keratinocytes and mesothelial cells. In Cell Growth and Division. A practical approach. R. Baserga, editor. IRL Press, Oxford, UK. 81-94.

17. Stallcup, M.R., and L.D. Washington. 1983. Region-specific initiation of mouse mammary tumor virus RNA synthesis by endogenous RNA polymerase II in preparations of cell nuclei. J. Biol. Chem. 258:2802-2805.

18. Wang, A.M., M.V. Doyle, and D.F. Mark. 1989. Quantitation of mRNA by the polymerase chain reaction. Proc. Natl. Acad. Sci. USA. 86:9717-9721.

19. Maniatis, T., E. Fritsch, and J. Sambrook. 1989. Molecular Cloning. A Laboratory Manual. Cold Spring Harbor Laboratory, Cold Spring Harbor, New York. pp. 7.52

20. Feinberg, A.P., and B. Vogelstein. 1983. A technique for radiolabeling DNA restriction fragments to high specific activity. Anal. Biochem. 132:6-13.

21. Wong, G.G., J.S. Witek, P.A. Temple, K.M. Wilkens, A.C. Leary, D.P. Luxenberg, S.S. Jones, E.L. Brown, R.M. Kay, E.C. Orr, et al. 1985. Human GM-CSF: molecular cloning of the complementary DNA and purification of the natural and recombinant proteins. Science (Wash. DC). 228:810-815.

22. Sallusto, F., and A. Lanzavecchia. 1994. Efficient presentation of soluble antigen by cultured human dendritic cells is maintained by granulocyte/ macrophage colony-stimulating factor plus interleukin 4 and downregulated by tumor necrosis factor $\alpha . J$. Exp. Med. 179:1109-1118.

23. Bratton, D.L., Q. Hamid, M. Boguniewicz, D.E. Doherty, J.M. Kailey, and D.Y.M. Leung. 1995. Granulocyte macrophage colony-stimulating factor contributes to enhanced monocyte survival in chronic atopic dermatitis. J. Clin. Invest. 95:211-218.

24. Kupper, T.S., F. Lee, N. Birchall, S. Clark, and S. Dower. 1988. Interleukin 1 binds to specific receptors on human keratinocytes and induces granulocyte macrophage colony-stimulating factor mRNA and protein. J. Clin. Invest. 82:1787-1792.

25. Tokura, Y., J. Yagi, M. O’Malley, J.M. Lewis, M. Takigawa, R.L. Edelson, and R.E. Tigelaar. 1994. Superantigenic staphylococcal exotoxins induce T-cell proliferation in the presence of Langerhans cells or class II-bearing keratinocytes and stimulate keratinocytes to produce T-cell-activating cytokines. $J$. Invest. Dermatol. 102:31-38.

26. Arai, K., A. Lee, A. Miyajima, S. Miyatake, N. Arai, and T. Yokota 1990. Coordinators of immune and inflammatory responses. Annu. Rev. Biochem. 59:783-855

27. Wood, L.C., S.M. Jackson, P.M. Elias, C. Grunfeld, and K.R. Feingold. 1992. Cutaneous barrier perturbation stimulates cytokine production in the epidermis of mice. J. Clin. Invest. 90:482-487.

28. Nickoloff, B.J., and Y. Naidu. 1994. Perturbation of epidermal barrier function correlates with initiation of cytokine cascade in human skin. J. Am. Acad. Dermatol. 30:535-546.

29. Nakamura, Y., T. Ozaki, T. Kamei, K. Kawaji, K. Banno, S. Miki, K. Fujisawa, S. Yasuoka, and T. Ogura. 1993. Increased granulocyte/macrophage colony-stimulating factor production of mononuclear cells from peripheral blood of patients with bronchial asthma. Am. Rev. Respir. Dis. 147:87-91.

30. Till, S., B. Li, S. Durham, M. Humbert, B. Assoufi, D. Houston, R. Dickason, P. Jeannin, A.B. Kay, and C. Corrigan. 1995. Secretion of the eosinophil-active cytokines interleukin-5, granulocyte/macrophage colony stimulating factor and interleukin-3 by broncho-alveolar lavage $\mathrm{CD}^{+}$and $\mathrm{CD} 8^{+} \mathrm{T}$ cell lines in atopic asthmatics, and atopic and nonatopic controls. Eur. J. Immunol. 25:2727-2731.

31. Marsh, D.G., J.D. Neely, D.R. Breazeale, B. Ghosh, L.R. Freidhoff, E. Ehrlich-Kautzky, C. Schou, G. Krishnaswamy, and T.H. Beaty. 1994. Linkage analysis of IL-4 and other chromosome 5q31.1 markers and total serum immu- 
noglobulin E concentrations. Science (Wash. DC). 264:1152-1156.

32. Kay, A.B., S. Ying, V. Varney, M. Gaga, S.R. Durham, R. Moqbel, A.J. Wardlaw, and Q. Hamid. 1991. Messenger mRNA expression of the cytokine gene cluster, IL-3, IL-4, and GM-CSF in allergen induced late-phase cutaneous reactions in atopic subjects. J. Exp. Med. 173:774-782.

33. Massey, W., B. Friedman, M. Kato, P. Cooper, A. Kagey-Sobokta, L.M. Lichtenstein, and R.P. Schleimer. 1993. Appearance of granulocyte-macrophage colony-stimulating factor activity at allergen-challenged late-phase reaction sites. J. Immunol. 150:1084-1092.

34. Durham, S.R., S. Ying, V.A. Varney, M.R. Jacobson, R.M. Sudderick, I.S. Mackay, A.B. Kay, and Q. Hamid. 1992. Cytokine messenger RNA expression for IL-3, IL-4, IL-5, and granulocyte/macrophage colony-stimulating factor in the nasal mucosa after local antigen provocation: relationship to tissue eosinophilia. J. Immunol. 148:2390-2394.

35. Bentley, A.M. Q. Meng. D.S. Robinson, Q. Hamid, A.B. Kay, and S.R. Durham. 1993. Increases in activated T lymphocytes, eosinophils, and cytokine mRNA expression for interleukin-5 and granulocyte/macrophage colony-stimulating factor in bronchial biopsies after allergen inhalation challenge in atopic asthmatics. Am. J. Cell. Mol. Biol. 8:35-42.

36. Chodakewitz, J.A., T.S. Kupper, and D.L. Coleman. 1987. Keratinocyte derived GM-CSF induces DNA synthesis by peritoneal macrophages. J. Immunol. 140:832-839.

37. Szabolcs, P., D. Avigan, S. Gezelter, D.H. Ciocon, M.A.S. Moore, R.M. Steinman, and J.W. Young. 1996. Dendritic cells and macrophages can mature independently from a human bone marrow-derived, post-colony-forming unit intermediate. Blood. 87:4520-4530.

38. Vremec, D., G.J. Lieschke, A.R. Dunn, L. Robb, D. Metcalf, and K. Shortman. 1997. The influence of granulocyte/macrophage colony-stimulating factor on dendritic cell levels in mouse lymphoid organs. Eur. J. Immunol. 27: 40-44.

39. Witmer-Pack, M.D., W. Olivier, J. Valinsky, G. Schuler, and R.M. Steinman. 1987. Granulocyte/macrophage colony-stimulating factor is essential for the viability and function of cultured murine epidermal Langerhans cells. $J$. Exp. Med. 166:1499-1509.

40. Heufler, C., F. Koch, and G. Schuler. 1988. Granulocyte/macrophage colony-stimulating factor and interleukin 1 mediate the maturation of murine epidermal Langerhans cells into potent immunostimulatory dendritic cells. $J$. Exp. Med. 167:700-705.

41. Rupec, R., R. Magerstaedt, C.G. Schirren, E. Sander, and T. Bieber. 1996. Granulocyte/macrophage colony-stimulating factor induces the migration of human epidermal Langerhans cells in vitro. Exp. Dermatol. 5:115-119.

42. O'Sullivan, G.M., R. Sluyter, C.M. Boswell, R. St. C. Barnetson, and G.M. Halliday. 1996. Modulation of $\mathrm{Ia}^{+}$Langerhans cell numbers in vivo by cultured epidermis derived supernatants and by GM-CSF. Exp. Dermatol. 5:2837.

43. Kaplan, G., G. Walsh, L.S. Guido, P. Meyn, R.A. Burkhardt, R.M. Abalos, J. Barker, P. A. Frindt, T.T. Fajardo, R. Celona, and Z A. Cohn. 1992 Novel responses of human skin to intradermal recombinant granulocyte/macrophage colony-stimulating factor: Langerhans cell recruitment, keratinocyte growth, and enhanced wound healing. J. Exp. Med.175:1717-1728.

44. Tazi, A., F. Bouchonnet, M. Grandsaigne, L. Boumsell, A.J. Hance, and P. Soler. 1993. Evidence that granulocyte/macrophage-colony stimulating factor regulates the distribution and differentiated state of dendritic cells/Langerhans cells in human lung and lung cancers. J. Clin. Invest. 91:566-576.

45. Horsmanheimo, L., I.T. Harvima, A. Järvikallio, R.J. Harvima, A. Naukkarinen, and M. Horsmanheimo. 1994. Mast cells are one major source of interleukin 4 in atopic dermatitis. Br. J. Dermatol. 131:348-353.

46. Braunstein, S., G. Kaplan, A.B. Gottlieb, M. Schwartz, G. Walsh, R.B. Abalos, T.J Fajardo, and J.G. Krueger. 1994. GM-CSF activates regenerative epidermal growth and stimulates keratinocyte proliferation in human skin in vivo. J. Invest. Dermatol. 103:601-604.

47. Hancock, G., G. Kaplan, and Z. Cohn. 1988. Keratinocyte growth regulation by the products of the immune cells. J. Exp. Med. 168:1395-1402.

48. Marini, M., E. Vittori, J. Hollemborg, and S. Mattoli. 1992. Expression of the potent inflammatory cytokines, GM-CSF, IL-6, and IL-8 in bronchial ep ithelial cells of patients with asthma. J. Allergy Clin. Immunol. 89:1001-1009.

49. Davies, R.J., J.H. Wang, C.J. Trigg, and J.L. Devalia. 1995. Expression of GM-CSF, IL-8 and RANTES in the bronchial epithelium of mild asthmatics is down-regulated by inhaled beclomethasone dipropionate. Int. Arch. Allergy Immunol. 107:428-429. 